\title{
MONOCYTOSIS AS AN INDEX OF TNT ABSORPTION
}

\author{
BY
}

\author{
ALISON M. HAMILTON *
}

During the performance of routine full blood counts on men and women workers in a Royal Ordnance Factory handling trinitrotoluene (TNT), a rise in the absolute number of large mononuclear leucocytes (monocytes), was frequently observed. It was hoped that the presence of this rise might indicate early toxicity and so help to decide whether gastric or other symptoms in such a worker were due to TNT, or merely coincidental. Webster's urine test is useless for this purpose, since it merely indicates the excretion of TNT products, and not whether the patient is poisoned.

To test this hypothesis further, four groups of workers were taken and examined:

(i) Fifty-four workers in contact with TNT with gastric symptoms or other symptoms known to be produced by TNT intoxication, such as tightness in the chest, pallor and fatigue, and anilism (slatey-blue cyanosis).

(ii) Fifty-one workers in contact with TNT with no symptoms.

(iii) A hundred and two normal controls.

(iv) Forty non-contact cases with gastric symptoms.

\section{Methods}

In all cases a full blood count (including reticulocytes) was done in order to keep a check on the occurrence of any abnormality which might invalidate results.

Most of the patients with symptoms (contact and noncontact) were bled in the laboratory at the main surgery. A large number of the non-complaining contacts were done at the branch surgery on their own factory ' group,' and many of the normal controls (largely office staff) at work.

The blood used was capillary blood taken either from the lobe of the ear or from the thumb at the root of the nail, and the films stained by Leishman's method. In performing the count two hundred cells were always counted.

For the reticulocyte counts a small quantity of capillary blood was mixed with an equal volume of 20 per cent. brilliant cresyl blue in normal saline and incubated at $37^{\circ}$ for fifteen minutes. Films were then made and stained by Leishman's method.

For brevity in the text all monocyte counts are referred to as ' high' if the absolute figure is above 450 per c.mm., those below this being considered not to be raised. This figure was chosen after careful study of the ranges taken by a number of workers (Price-Jones, Vaughan and Goddard, 1935; Whitby and Britton, 1944; Todd and Sanford, 1941). The figure 450 proved to be greater than the mean actually observed in the normal controls in the present series.

* Late Pathologist and Assistant Medical Officer, Royal Ordnance Factory, Aycliffe, Co. Durham.

\section{Results}

When the investigation was completed, final analysis of the results showed a statistically significant rise in the two groups in contact with TNT, and none in the two non-contact groups. In the case of the complaining group, the mean was 730 and in that of the non-complaining, 722. The standard deviation of the means were respectively 360 and 305 . In the normal controls, on the other hand, the mean was 228 with S.D. 86, and the noncontact gastric subjects showed a mean of 291 with S.D. 130. It is to be noted that both the noncontact groups had the maximum of their range below the 450 chosen in the experiment as an arbitrary normal level. (The results are summarized in Table 1.)

TABIE 1

ANALYSIS OF RESULTS

\begin{tabular}{l|c|c|c}
\hline \multicolumn{1}{c|}{ Category } & $\begin{array}{c}\text { Number } \\
\text { of cases }\end{array}$ & $\begin{array}{c}\text { Mean } \\
\text { monocyte } \\
\text { count }\end{array}$ & $\begin{array}{c}\text { Standard } \\
\text { deviation } \\
\text { of mean }\end{array}$ \\
\hline Showing symptoms & 54 & 730 & 360 \\
Not complaining .. & 51 & 722 & 305 \\
Controls (normal) & 102 & 228 & 86 \\
Gastric controls.. & 40 & 291 & 130 \\
\hline
\end{tabular}

It was clear that workers in contact with TNT, whether with or without symptoms, tended to have high monocyte counts, and so it was not possible to use this test, as had been hoped, to differentiate toxicity from coincidental disease.

In order, however, to determine further that the monocytosis was really due to TNT, thirty cases were followed up which had showed monocytosis during contact and who had been taken off contact. Owing to absence or discharges only ten of these were examined at sufficiently regular intervals to be satisfactory material. The results of these examinations are given in fig. 1 . It will be noted that in these cases the count falls to normal two months after removal from contact, and that the level then lies approximately between 200 and 300 . The previous finding of a rise due to exposure to TNT was thus confirmed.

It was also found that gastric and other symptoms when present tended to subside at about the same rate as did the monocyte count, or rather more rapidly. 


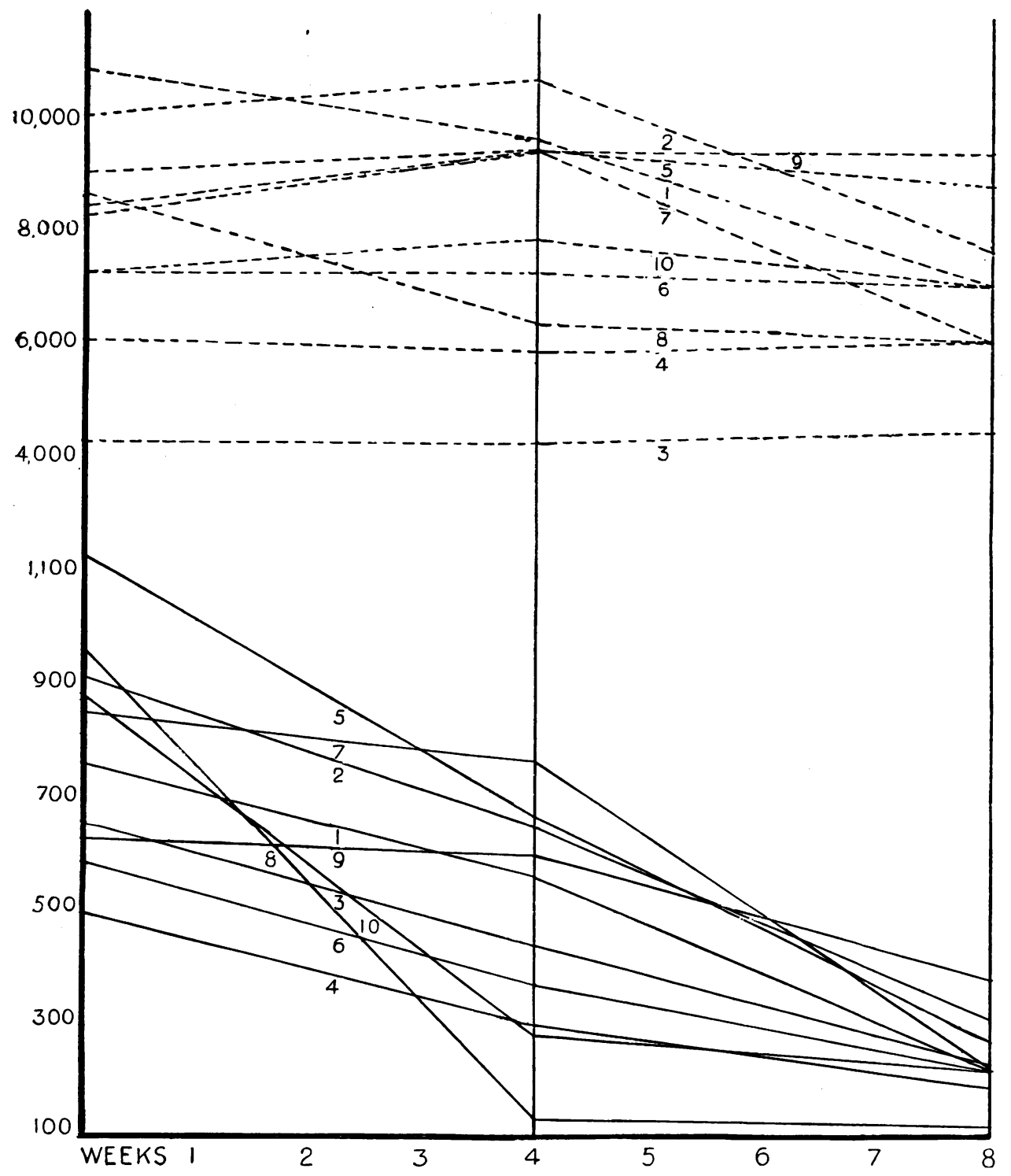

Further, it was observed that the intensity of the response was not proportional either to length of time of exposure or to heaviness of contact, and this fact has been noted by other workers in connexion with TNT jaundice and aplastic anaemia (Livingstone-Learmonth and Cunningham, 1916; Moore, 1917).

In a series of eight of the workers showing symptoms who had been in contact for periods ranging from two to six weeks, the mean monocyte count was 615. This is below the mean for the whole of that group (730), but above the figure 450 chosen as an upper limit of normality in this investigation. On the other hand, a male operative who had worked with TNT for ten years (one of the series in the non-complaining group), had a monocyte count of only 304 .

Intensity of contact was not so easy to assess, owing to the variety of operations and the tendency to change workers from one process to another. In the present series there were, however, two cases, both complaining of symptoms, who were on work in which contact was known to be light, and they had monocyte counts of 644 and 860 respectively. Furthermore, of the series of fifty-four workers with symptoms, nineteen were inspectors and not operatives, and the manual contact with TNT was, in their case, considerably less than it was in that of the operatives in the filling shops. Of these nineteen, sixteen had monocyte counts above $\mathbf{4 5 0}$.

\section{Discussion}

Previous work on TNT has been largely directed towards its toxic effect upon liver and bone marrow (Livingstone-Learmonth and Cunningham; and Moore). When the circulating blood has been 
examined it has almost always been with reference to the count of the red blood corpuscles, the haemoglobin percentage and the polymorph-lymphocyte ratio (Panton, 1921; Stewart, 1917; Cone, 1944). An eosinophilia has sometimes been noted (Stewart; Cone), but in the hundred TNT contacts under review at present only sixteen showed an absolute eosinophil count above 250 . With regard to the polymorph-lymphocyte ratio, only six in the series had a lymphocytosis. Twenty-two had a mild leucocytosis of over 10,500 , fourteen of these having an absolute increase in polymorphs. (In deciding the upper limit of normality, the criteria suggested by Kracke (1941) were adopted: normal range of polymorphs $3000-7000$; of lymphocytes, 1000 4000).

The reticulocyte response to TNT absorption has also been studied (Davie, 1941; Stewart, Witts et al., 1944) and a reticulocytosis has been found to occur which is at its peak a few days after removal from contact. No reticulocytosis was ever observed in any of the present series while in contact, although cases were examined whose periods of contact varied from two weeks to ten years. There were no facilities for examining them when just removed from contact.

With regard to a monocytosis in the presence of TNT, almost no reference could be found to it in previous work. There was only a passing mention by Browning (1944) to its variable occurrence. A definite monocytosis has, however, been observed in the presence of the allied substances aniline and benzene, and with tetrachlorethane, and was first noted by Malden (1907) in aniline workers. Selling and Osgood (1938) noted a rise up to 7 per cent. in a series of twenty-eight cases in contact with benzene, and Smith (1928) in a series of seventy-nine women, records similar findings. In the case of tetrachlorethane, Hunter (1944) quotes Minot and Smith (1921) as having found an increase up to 40 per cent. in workers exposed to this substance, and Parminter (1921) as using this monocytosis as a test of early poisoning among such workers. Beck (1938) also notes tetrachlorethane poisoning as a cause of monocytosis.

If, as is suggested by Beck, the chief cause of a monocytosis is foreign matter in the blood-stream such as degenerated cells, it seems possible that there may be a monocytosis in response to an exogenous poison which on absorption, even in minute quantities, damages the liver and bone marrow cells. This may occur when the concentration is such as can easily be dealt with in the otherwise healthy organism. Kracke mentions that a monocytosis has been observed in subacute infections, where the toxin is, obviously, endogenous and occurring in relatively small and steady amounts.
Monocytosis, therefore, whilst occurring in the presence of TNT absorption, is not considered to be a specific response, but incidental only.

\section{Conclusion}

From the above investigations it appears that contact with TNT causes a rise in the monocyte count, irrespective of the presence of symptoms, and that neither heaviness of contact nor length of exposure seems to be the determining factor in the intensity of the response.

Clinically the test is useful when it is desired to differentiate between a real TNT gastric syndrome persisting after removal from contact and similar symptoms due to other causes occurring in those who have recently been working with TNT but have been removed to non-contact work. It remains positive for several months, and therefore can be used to show the presence of absorption effects long after Webster's test would have become negative.

\section{Summary}

A study of a hundred and five individuals exposed to a TNT hazard and of a hundred and forty-two individuals not exposed to TNT has shown that an early reaction to TNT poisoning is a rise in the large mononuclear leucocyte count.

This rise is reversed within two to three months after removal from TNT contact.

The monocyte rise appears usually to precede any symptoms of illness and seems likely to be an early physiological reaction to TNT.

It is suggested that this monocyte rise may be of use in the differential diagnosis of TNT poisoning.

\section{Acknowledgments}

Thanks are due to Dr. C. V. Harrison for valuable guidance and criticism; to Dr. G. Herdan for a statistical assessment of the results; and to Mrs. J. Barrett for her skilled assistance in the performance of the haematological tests.

\section{REFERENCES}

Beck, R. A. (1938). Laboratory Manual of Hematologic Technic. W. B. Saunders Company, London and Philadelphia.

Browning, Ethel (1944). Ministry of Supply medical post-graduate

Cone, T. E., Jr. (1944). J. industr. Hyg., 26, 260.

Cone, T. E., Jr. (1944). J. industr. Hyg., 26, 260.

Hunter, Donald (1944). Industrial Toxicology. Clarendon Press,

Kracke, R. R. (1941). Diseases of the Blood. J. B. Lippincott, Lond Livingstone-Learmonth, Agnes, and Cunningham, Barbara M. (1916)

Lancet, 2, 261.
Malden, W. (1907). J. Hyg., Camb., 7, 672.

Moore, B. (1917). Spec. Rep. Ser. Med. Res. Counc., Lond., 11.

Panton, P. N. (1921). Spec. Rep. Ser. Med. Res. Counc., Lond., 58 Price-Jones, S., Vaughan, Janet M., and Goddard, Helen M. (1935). J. Path. Bact., 40, 503 .

. Palh. Bact. AO E (1938) In Handbook of Hematology, IV, 2693. (Hal Downey.) Hoeber, N.Y.

Smith, Adelaide. Ibid., 2714

Stewart, Alice, Witts, L. J., Higgins, G., and O'Brien, J. R. P. (1945) Brit. J. industr. Med., 2, 74.

Brit. J. industr. Med., 2, 74. 153.

Todd, J. C., and Sanford, A. H. (1941). Clinical Diagnosis by Laboratory Methods. W. B. Saunders Company, London and Philadelphia. Whitby, L. E. H., and Britton, C. J. C. (1944). Disorders of the
Blood. J. and A. Churchill, London. 